\title{
The role of "not for profits" (NFPs) in disaster preparedness in Aotearoa New Zealand
}

\author{
Sharon Torstonson and Denise Blake \\ Joint Centre for Disaster Research, School of Psychology, Massey University, \\ Wellington, New Zealand \\ Darrin Hodgetts \\ School of Psychology, Massey University, Albany, New Zealand, and \\ David M. Johnston \\ Joint Centre for Disaster Research, School of Psychology, Massey University, \\ Wellington, New Zealand
}

Role of NFPs in disaster preparedness

\begin{abstract}
Purpose - The purpose of this research is to highlight the role of not-for-profit (NFP) organisations in enhancing disaster preparedness. The authors set out to understand their perspectives and practices in regard to disaster preparedness activities to support people who live precarious lives, especially those who live as single parents who are the least prepared for disasters.

Design/methodology/approach - The research draws on in-depth, semi-structured interviews with 12 staff members, either in a group setting or individually, from seven NFP organisations, who were located in Ötautahi (Christchurch) and Kaiapoi in Aotearoa New Zealand. These participants were interviewed eight years after the 2011 Christchurch earthquake.

Findings - Four key narrative tropes or elements were drawn from across the interviews and were used to structure the research results. These included: "essential" support services for people living precarious lives; assisting people to be prepared; potential to support preparedness with the right materials and relationships; resourcing to supply emergency goods.

Originality/value - This research contributes to disaster risk reduction practices by advocating for ongoing resourcing of NFP groups due to their ability to build a sense of community and trust while working with precarious communities, such as single parents.
\end{abstract}

Keywords Preparedness, Precarity, Not for profit, Single parents

Paper type Research paper

\section{Introduction}

With rising income inequality and ongoing social security reforms, people living precarious lives continue to struggle to meet the demands of ordinary everyday times, let alone when extraordinary events occur (Lassa, 2018; Rashbrooke, 2014). Whilst many respond to adversity agentively and with considerable resilience, their dwellings are often overcrowded, poorly built, have weak foundations and little or no insulation. Most have to cobble together basic resources to pay for rent, utilities and purchase food and face considerable barriers to their participation in civic life (Groot et al., 2017; Hodgetts and Stolte, 2017; Tierney, 2019). Further, efforts to promote emergency management preparedness generally are founded upon the assumption that people have the capacity and resources to prepare (e.g. see Christchurch City Council, 2020; Wellington Regional Emergency Management Office, 2018).

The authors would like to acknowledge the following funding sources in undertaking this research: Massey University, Resilience to Nature's Challenges National Science Challenge and QuakeCore.

Funding: This project was partially supported by Te Hiranga Rū QuakeCoRE, a New Zealand Tertiary Education Commission-funded Centre and the National Science Challenges: Resilience to Nature's Challenges Kia manawaroa - Ngā Ākina o Te Ao.

Received 28 October 2020 Revised 30 October 2020 18 December 2020 18 December 2020 Accepted 19 December 2020 
Many public preparedness messages overlook how people living precarious lives (King et al., 2017; Standing, 2011) live with an inability to prepare by stockpiling additional food or safety equipment. It is crucial to remain heedful that lives of precarity consist of "disaster" conditions and, as such, initiatives should address the existing social concerns such as little capacity to prepare. As such, it is important to enable people to have equitable access to safety and security when enduring additional disadvantage during disasters (Blake et al., 2017a).

The purpose of our broader project was to understand what enables and constrains people living precarious lives, such as single parents, to have access to just outcomes in disaster contexts. We were particularly interested in single parents as this group has been identified as the least prepared for disasters and at increased risk of living in substandard rental dwellings (Statistics New Zealand, 2012). In this article, we draw on the expertise of not-forprofit (NFP) service providers to consider the potential for these agencies to contribute more fully to disaster resilience for single parents by providing practical skills and resources to aid single-parent households in preparing for disasters (Social Equity and Wellbeing Network Tuia te Oranga, 2015). While we recognise that disaster phases are not discrete, but multilayered, iterative and complex, we use them as a useful heuristic tool for describing particular aspects of disasters (Neal, 1997; Tierney, 2019). Our lens is directed at the readiness and reduction phases of disaster management as used by Aotearoa New Zealand's Ministry of Civil Defence and Emergency Management (2019) (now called The National Emergency Management Agency Te Rākau Whakamarumaru) Readiness involves understanding risk and taking steps to reduce the impact of those risks. At the same time, reduction focusses on the systems and capabilities, such as building responsive programmes for the public or ensuring critical infrastructure services are operational. Response and recovery include the immediate actions taken after a disaster event to protect people, and property and recovery refer to the regeneration of communities (National Emergency Management Agency, 2020). The present study also addresses the gap in knowledge about the role of NFPs, single parents and disaster preparedness.

\section{Literature on the "essential" role of not-for-profit (NFP) organisations}

NFP organisations serve people and communities across a range of spheres, including social and material support services, education, culture, health, sports, conservation and emergency management (Statistics New Zealand, 2018). These organisations have also demonstrated some capacity to enhance hazard governance through mobilising local actors, promoting disaster risk reduction, climate change adaption and activism (Gibson and Wisner, 2019). In 2018, the NFP sector made an economic contribution of $12.1 \mathrm{bn}$ dollars and $159 \mathrm{~m}$ volunteer hours in Aotearoa New Zealand (Statistics New Zealand, 2020a). Predominantly grassroots, NFPs can be approached as non-commercial, not concerned with providing profits for shareholders or directors and organisations whose surplus revenue is redistributed in ways that uphold the aspirations of the organisation (Gibson and Wisner, 2019; Lassa, 2018; Not For Profit Resource, 2017). Doing the work recent governments tend to ignore or contract out to the private sector, NFPs have been touted as an "inexpensive" and more direct way to support a range of personal and community needs (Lassa, 2018). Correspondingly, these organisations often operate with little funding, which regularly overburdens staff in terms of workloads and often results in reduced capacity to assist people in need (Gibson and Wisner, 2019). Notwithstanding these constraints, a spotlight on NFP in Aotearoa New Zealand during COVID-19 illuminated their "essential" role in ensuring the provision of critical health, disability, social and care services in ordinary and extraordinary times (Ministry of Health, 2020).

Reviewing the significance of NFP organisations at the global and local level over 70 years, Lassa (2018) traced the distinctive role of NFP in disaster management and disaster resilience, noting that many such organisations have proved invaluable in fostering community cohesion and social capital (Aldrich, 2012; Blake, 2018; Jovita et al., 2019; Putnam, 
2001). Social capital, a well-known element in adaptive disaster recovery, is conceptualised as bridging, bonding and linking capital. Bridging capital is the relationship between groups, bonding the relationships within groups and linking capital recognises the relationships between diverse groups with different social positions (Aldrich, 2012; Claridge, 2018; Putnam, 2001). Also considered relational capital, these positive human relations constitute supportive connections amongst people, community attachments and increased opportunities for civil participation for precarious groups (Perkins and Long, 2002; Small, 2009).

In the present research, we also draw on notions of a psychological sense of community to delineate how NFPs can act as conduits to connection, belonging, mutual responsibilities, social wellness (McMillan, 2011) and ultimately disaster risk mitigation. While multiple interpretations surround a sense of community, Pretty et al. (2006) argue that it is important for any definition to pay attention to the innate interpersonal processes that shape community life, how community relations enable services and how these factors matter for cultivating well-being. Communities are complex systems of interconnected actors who can work within and towards a shared ethic, aim or social project that can contribute to disaster resilience (Twigg, 2009). Boyd and Martin (2020) propose that NFPs are often central to the cultivation of values of care, trust, sharing and support in communities living with adversity. It is the trusting and cooperative relationships that NFP workers develop with groups and communities that government agencies often overlook or find hard to reach that can prove particularly valuable during emergencies.

In disaster management, the salient role of NFP organisations emerged during the 1980s in response to diminishing financial security and increasing poverty globally due to the neoliberal delegation of social responsibility from the state to communities (Benson et al., 2001; Lassa, 2018). With punitive and inequitable social practices still damping the well-being of many, some NFPs recognised that they had the unique opportunity to contribute to disaster preparedness for the clients and the communities with whom they work. We have seen this play out in Aotearoa New Zealand over the past decade with the large-scale and significant disasters that have transpired (2011 Christchurch Earthquake, 2016 Kaikoura earthquake, 2017, Edgecombe floods, 2019 Mosque Attack, 2019 Whakaari White Island Volcanic eruption and the 2020 COVID-19 pandemic). NFPs have been particularly pertinent during the COVID-19 pandemic; for instance, the Blind Foundation provides disaster preparedness resources on their website for both COVID and other civil defence emergencies (Blind Low Vision NZ, 2020).

Endorsing the importance of resilient communities by drawing on a "whole of society approach", the UN Sendai Framework for Disaster Risk Reduction (Aitsi-Selmi and Murray, 2015; United Nations, 2015) and the Aotearoa New Zealand National Disaster Resilience Strategy (Ministry of Civil Defence and Emergency Management, 2019) argue for practical strategies for mitigating exaggerated risks and promoting the use of shared community knowledge to prevent disaster harm and risk for groups living in precarious situations. Central is the call to enact responses that are culturally and socially targeted to diverse community needs (Allen, 2006). Mitigating the complex social and systemic issues that are exposed during disasters requires collaborative efforts (Twigg, 2009). Further, statutory authorities responsible for increasing disaster readiness and resilience should appreciate the potential of the NFP sector to reach, engage and educate communities with vulnerability.

A number of studies have explored the role of NFP organisations in improving the efficacy of disaster response and recovery where many serve communication, coordination and distribution functions (Benson et al., 2001; Curnin and O'Hara, 2019; Kapucu, 2007, 2008; Sledge and Thomas, 2019). In such studies, NFP are characterised as non-profit, voluntary, community, welfare and non-government organisations (NGOs); they are predominantly situated as grassroots and non-commercial (Gibson and Wisner, 2019; Lassa, 2018; Not For Profit Resource, 2017). In the context of Ōtautahi (Christchurch) following the earthquakes,

Role of NFPs in disaster preparedness

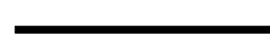


the role of NGOs was explored by Cretney (2016), Good et al. (2016) and Vallance and Carlton (2015). However, there seems to be limited research focussing specifically on NFP and disaster preparedness. A 2015 Australian report did investigate issues of vulnerability and emergency management to garner the types of initiatives untaken by NFP groups who engage daily with people living precarious lives. It was found that ongoing, daily encounters with people using their services enabled NFP staff to develop positive and trusting relationships, which in turn built resilience (Vulnerable Sections of Society Working Group Community Engagement Subcommittee, 2015). Other research (Sledge and Thomas, 2019) raised questions around capacity in the NFP sector to contribute to building disaster resilience through enabling preparedness actions with people using their services. Questions abound about what resources NFP have and what barriers they face in their everyday practice and disaster risk mitigation actions. To start identifying elements that might influence the sector's capacity, this research project aimed to address these questions by exploring how NFPs worked with groups that have historically had limited preparedness capability.

\section{Method}

Participants

NFP social service agencies in greater Ōtautahi (Christchurch) and Kaiapoi Aotearoa New Zealand were identified through the first author who has a long history of service in the NFP sector. The first author invited potential participants to take part in semi-structured narrative interviews to share their experiences and knowledge about working with single parents in the area of disaster preparedness. Seven agencies agreed to take part in total. In one agency, five staff members engaged in a group version of the interview and in a different agency two staff members were interviewed separately. In all the other agencies, a single senior staff member took part (12 individual participants in total). Conferring with Guest et al. (2006), we reached data saturation with this number of interviews. Only four of the 12 participants were in their roles at the time of the Canterbury Earthquake sequence 2010/2011. The other participants were not working in their current roles. In three of the agencies, the participants had managerial as well as client responsibilities, while the other four agencies provided staff whose single responsibility was working with precariat communities. We opted to engage with a contained group of 12 participants to draw out and engage more thoroughly with the nuances of their accounts as experienced key informants in the sector. It was expected that having endured the major Canterbury earthquakes of 2010 and 2011 some eight years earlier would have contributed to enhanced awareness about disaster management and action to support disaster preparedness for people who use their services. Participants were asked what level of preparedness they had observed in single parents who use their services in particular and what role they had or could have in enhancing people's preparedness activities.

\footnotetext{
Analysis

The interview accounts were transcribed verbatim and analysed using an interpretive narrative approach (Pence, 2004; Pinnegar and Daynes, 2007; Polkinghorne, 1995). This approach orientated us to how storytelling offers a way for participants to make sense of lived experience and gain insight into how people navigate the world. That involved firstly exploring the meaning that the participants made about their work in an NFP organisation and secondly examining what they did in relation to emergency management preparedness actions. From this analysis, we offer general recommendations to support NFPs should they want to provide disaster preparedness education or resources. However, we recognise that this is a small sample of NFP organisation and that the findings do not represent all NFP groups. We also appreciate that there can be a tension between the purchase of government-
} 
specified services and agency for the NFP organisation in regard to whose interests and agendas are being met (O’Brien et al., 2009).

Role of NFPs in

\section{Findings}

Four key narrative tropes or elements were drawn on repeatedly across the interviews and were used to structure our analysis. These were: (1) "essential" support services for people living precarious lives; (2) assisting people to be prepared; (3) potential to support preparedness with the right materials and relationships; (4) resourcing to supply emergency goods. These four tropes explicate the importance of increasing the ability of NFP organisations to provide "essential" services that include advocating for disaster preparedness for groups such as single parents who live disadvantaged lives due to low incomes or housing insecurity.

\section{"Essential" support services for people living precarious lives}

This section foregrounds how participating NFP organisations provide necessary bridging and linking capital for their precariat members. Often precariat groups, such as some single parents, have limited social and financial capital and need assistance to meet the demands of their everyday lives. However, engaging with government agencies can be troublesome due to cultural and linguistic differences, literacy levels (Blake et al., 2017a, b) and physical or mental health conditions. These issues are compounded when government policies disregard the contextual characteristics that drive precarity (Hodgetts et al., 2014). NFP organisations can act as advocates on behalf of people across a range of services, such as welfare and health agencies. Participants in this research reflected on their advocacy and support roles, noting the importance of their presence in the lives of single parents who use their services. In the following interview example, the participant describes this as "walking" alongside:

And it's just about walking the journey with families and being a bit of a mentor and being a person that they can go to when things are happening. They want some solid advice and some solid support and advocacy, especially when dealing with places like Courts and Lawyers and Work and Income and IRD and all those kind of places. (Eva)

The "support and advocacy" of NFPs were particularly pertinent after the 2011 Christchurch earthquake, which caused the death of 185 people (New Zealand Police Ngā Pirihimana o Aotearoa, 2012) and injured and displaced many more. The following participant recounted some of the obstacles that were encountered with no preparedness plan in place:

... immediately after the earthquake a lot of them I know utilised the Community Shelters because they just didn't have a plan. They didn't have food. They did not feel safe in their house, or their house was damaged. The sewerage wasn't working. (Kathy)

As well as disrupting access to food, housing and sanitation, the earthquake damaged public transport, schools and day-care services. When these services closed, NFPs were called on for additional social support:

I think a lot of the mothers in the group are already living in survival mode. . . the pre-school was quite important, and it was shut down for a very short period of time, but that kind of connecting in and then being able to [see us]..., that's when they would come for some of that support. (Kathy)

Here the participant talks about providing emotional and psychological support in the very traumatic immediate aftermath of the earthquake. This NFP agency was able to offer safety, social bonding and a sense of community. Another participant proposed that their singleparent clients trusted them because they were reliable witnesses to their precarity and provided a safe non-judgemental space to be around. They also recognised that while their clients might survive for a few weeks following a disaster, having people to shore them up in times of distress is essential: 
I think, because we're their safe place, you know, say even working with whānau (family) and they may not be ready at the time they might survive for a few weeks, they always know that they can come, that our door is open. (Awhina)

Having an "open-door" policy is not unusual in NFP organisations. Such policies provide assurance to communities that someone is there when needed. Having someone to turn to for support is protective during a disaster, in that it decreases the risk of severe trauma and distress, according to the Ministry of Health (2016). Another participant worked for an agency attached to a Church, serving an ethnic community. For this community, "the Church has a role of social responsibility amongst its members" (Mele). This quote aligns with research by Boyd and Martin (2020), who identified that social responsibility fortifies a sense of community.

With an enveloping approach, people using NFP services are more likely to respond positively to initiatives by NFP agencies, rather than government agencies where they have little established goodwill due to an often long history of poor treatment and disrespect towards members of the precariat (Hodgetts et al., 2014). NFPs with their ethos of care demonstrate how they can utilise social capital and a psychological sense of community to support disaster preparedness, response and recovery (Aldrich, 2012; Jovita et al., 2019). In this vein, as the following excerpt implies, NFP organisations know the challenges families face and endeavour to do what they can to provide people with a sense of control over their lives:

Must be a really horrible place to be, feeling like you're responsible for the lives of your little people, of your children, and not feeling like you had it together yourself. That must be a very scary place to be. So, empowering people to know that you don't have to have everything on that checklist, but do the best that you can and that's all you can do and that safety is the priority. Making sure everybody is safe. (Eva)

Feeling safe, that experience of ontological security where people believe that they will be awake in a world that is known, stable and predictable is pivotal after a disaster, especially when access to life-enhancing preparedness items is not possible due to financial and social precarity (Blake et al., 2017a; Giddens, 1991; Hawkins and Maurer, 2011; Tierney, 2019). When aspiring to promote community resilience for all, participant narratives remind us that people working in the disaster risk management field should account for equitably access to resources or wider social capital. And while organisations such as NFP are understood as "essential" during crises such as a pandemic, they should be given adequate remuneration or funding in order to reflect their "essential" role (Living wage Aotearoa New Zealand, 2020).

\section{Assisting people to be prepared}

This section explores what NFP participants in this research did or did not do in regard to assisting their single-parent clients to be prepared for future disasters. Despite experiencing the 2010 and 2011 Canterbury earthquakes, only one person in this study identified themselves as having the wherewithal to advocate for disaster preparedness and resilience explicitly in their subsequent work with single parents. Neither did it appear to be a common practice in the wider NFP sector in Otautahi. When asked, none of the interviewees knew of any other agencies or colleagues that included disaster preparedness purposely in their work or had it as an organisational policy.

The one participant who encouraged people to be prepared did so as a personal initiative, as opposed to an organisational mandate. They recognised the barriers members of the precariat face in preparing and accepted that it would be almost impossible for them to have the necessary resources, such as extra food and batteries. However, rather than fearing any disempowerment by being asked to prepare, they believed that taking even small actions would enable people to gain more of a sense of agency over their lives: 
What I did initially after the quake was I went onto the Civil Defence website and downloaded their checklists. What do you need to be prepared, and also did a list of emergency numbers, generally 0800 numbers cos' most of our clients don't have a lot of credit on their phone. So, something they could ring from their cell phone if there was an emergency and going through that checklist and helping them put a survival pack together. ... you couldn't tick every box, but as much as we could we ticked as many as we could and I think just that feeling of preparedness, being prepared, was a little bit of a sense of a relief and having a list of people that you could contact if you were afraid. (Eva)

Role of NFPs in disaster preparedness

This participant asserts that simple acts such as completing a checklist can assist people in achieving some sense of ontological security, even if momentary. Eva also recognises that access to checklists requires access to the Internet and perhaps a printer which is problematic when on a low income. Similarly, having a working phone to make urgent calls during an emergency might be impossible depending on who needs to be contacted. Prepaid mobile phones, commonly used by people on limited incomes in Aotearoa New Zealand, can connect to 0800 or emergency numbers without credit. The limited ability to contact friends or family is concerning given the reliance on mobile devices for response strategies (Tan et al., 2017), such as contact tracing during pandemics.

Further reflecting the importance of a sense of agency and security, other participants saw little point in assisting single parents to prepare by putting aside emergency supplies of food and water because they do not have the resource capacity to support such actions. One participant in particular demonstrated reluctance to even distribute generic disaster preparedness material, such as the Get Ready Get Through resource due, to concern about any potential frustration, heightened sense of futility and insecurity it might cause clients:

The downside would be if someone gets that leaflet and it's so undoable, unachievable, that it actually makes them more, feel more distant, more disengaged from society, cos I think that's what everyone else does, and I haven't got a hope in hell of a chance of actually being able to do that..... That's how you take it cos when you're in that position you feel quite criticised and judged, so it doesn't take much to tip that over. (Helen)

"Tipping over" is a genuine concern for professionals who work with people who struggle with attaining fundamental human rights, such as food or shelter. As presented by Blake et al. (2017a, b), systems such as emergency management potentially (re)produce systemic violence because people are devoid of the ability to prepare for an emergency or disaster, even though they are encouraged to do so. Structural violence in this work represents the harm that is inflicted when agencies inhibit people's agency to act, which in turn negatively impacts their somatic and psychological well-being (Farmer, 2004; Ho, 2007). Another participant also expressed concern, quite rightly, that when people are unable to achieve preparedness tasks, it can reinforce notions of inadequacy or failure for groups who already experience social stigma and discrimination. While this concern was not put forward by other participants, several concurred when it was put to them by the interviewer.

Another barrier was training. Some participants reported not having specific emergency management training on how to best help people prepare or cope during an earthquake. Without such training, they developed pragmatic strategies to support the people they worked with as they went about their work:

... we were not given a lot of tools on how to handle it, ourselves, with clients. So like I said, you know, every individual worker almost had to think on their feet and come up with their own plan. (Eva)

Without the tools to know how to support people to cope after a disaster, the NFP workers in this study recounted innovation by developing fit-for-purpose plans when working with their service users. According to Rapeli and Mussalo-Rauhamaa (2017), social services such as institutions of care and sheltering housing need to ensure they are well prepared because 
people with complex needs are dependent on their services. Extending this claim, we assert that it would be prudent for NFP organisations to have preparedness plans or training to ensure that workers engage with people who rely on their services in ways that are useful, respectful and empowering in times of distress.

When explaining why they were not involved in disaster preparedness with people, participants also outlined how their work programme and deliverables were restricted by the terms and conditions of government contracts and other funding agreements. The time and space to also dedicate to disaster preparedness and response were presented as "hard to find" (Gwen) for some. Others suggested possible options of including disaster preparedness concepts into pre-existing courses:

I'm just thinking about links to the curriculum; there must be somewhere ... you could link some of this stuff in with some NCEA achievement standards for students to give it a bit more meaning. ... We walk a tightrope of academic progress and success and life, in terms of like pastoral needs and life lessons and life learning and parenting, and all those kind of things. (Sonya)

For this participant, working with younger parents in a school setting invited the possibility of adding disaster preparedness planning to other curricula, as also indicated by Tipler et al. (2017). However, as expected, trying to balance parenting and everyday schooling demands could be challenging for the parents. While participants understood the value of promoting disaster resilience, they also recognised the complexity of wider contextual challenges with which single parents and other members of the precariat contend. Regrettably, disaster preparedness actions are not a priority for many (Blake et al., 2017a, b), due to everyday hardships such as living with insecure housing, low incomes and relationship difficulties (Rua et al., 2019).

\section{Potential to support preparedness with the right materials and relationships}

All of the participants saw potential in working with people to enhance their disaster resilience. Several were particularly enthusiastic when discussing potential avenues to support single-parent families to be prepared. Expressing deep aroha for the people with whom she worked, the following participant became animated about wanting them to be "okay and resilient and resourceful":

Cos' we do deeply care about our families [clients], well I do, ... and I want them to be okay and resilient and resourceful when they need to be ... (Eva)

The need to disseminate information in appropriate formats and through appropriate channels is well recognised in the disaster space (Blake et al., 2017a, b). Poorly designed communication and an overreliance on technology are problematic for people with disabilities, language issues or financial constraints (Blake et al., 2017a, b; Good et al., 2016). In a review of literature about people with vulnerabilities and preparedness, Beckjord et al. (2008) found that the most ineffective form of risk communication for such groups is messages that are given too early and too often. It is more useful to disseminate information in multiple formats (e.g. television, print (verbal and pictorial), audio, Internet, interpersonal). Disaster messaging should also be tailored to meet local needs and be personally relevant (including linguistically) (Blake et al., 2017a, b).

The perceived lack of appropriate material to assist people who use NFP services presented challenges for the participants in this work. Even though all of the participants worked in Ötautahi or Kaiapoi, which are still in the rebuilding phase of recovery from a significant earthquake, all discussed how general disaster information and/or plans still needed to be designed with the needs of their single-parent clients in mind. Participants spoke of the importance of not overwhelming clients with information. Any additional information should be presented in a format that is economical, not over complicated and with clear and 
simple recommendations that can be actioned. This might involve infographics with Role of NFPs in minimal text:

I know that with some of the plans that I did for parents and for the children we used pictures, cos it was a lot easier. You know, like a safe place. So we'd put a cross or something, and that would be a symbol for the safe place. So, making it manageable for the people that are going to use it or where they are. (Eva)

I would see that it would be at the level of, you know, asking Dads or checking with Dads, do they know where their local centre is and because I think that's all that the Dads would be able to handle. ... I guess some sort of information like on a pamphlet or something like that where it gave some basic instructions on what to do and whatever and then they could write the name of their local centre on it, makes sense. (Brian)

In looking to adapt the generic disaster resilience material for their clients, the participants can be seen to be taking on the role of cultural mediators, taking concepts and language that are not readily accessible by their clients and connecting it to the realities of their lives. As participants knew relatively little about disaster preparedness and resilience themselves, they felt unprepared for this role and unable to produce these resources for themselves. They argued for specific and detailed information that they could then work through with their clients:

If I can print off a sheet of Get Ready Get Thru that talks me through step-by-step what I need to have thought about or have a plan around in terms of an event, when a disaster happens, then that would just make it easier. (Sonya)

Others identified the importance of having a centralised educator who could host workshops on disaster and risk preparedness information; this information is normally generic and accessed from the local City Council:

We will from time to time prepare our awareness programmes. We do have awareness programmes whenever we have materials and information from the City Council. We host an information day where all those are being discussed. (Mele)

Many of the strategies suggested by the participants would require a working relationship with other institutions, such as the civil defence and disaster resilience authorities. Having working relationships in a "whole of society approach" is important to good recovery as recognised in the Ministry of Civil Defence and Emergency Management (2019) strategy:

Communities, including the private and not-for-profit sectors, are empowered to respond and recover as they see fit while having connections into official channels to source support and resources where needed. (p. 30).

However, there was little evidence of any such connections to official channels for the agencies in this research, with participants typically relying on immediate resources and developing what knowledge they did have from publicly available sources such as websites and brochures. This lack of connection to government agencies is echoed by Australian nonprofit groups in the aftermath of the Blue Mountains fires of 2013 (Ingham and Redshaw, 2017). Official government agencies were ill-prepared for working with NFP groups during and after the fires and most NFP groups were unaware of the existence of the Local Emergency Management Committee. In turn, the Local Committee was unaware of the extent of the non-profit sector in their area and their connection to vulnerable communities that were affected by the fires. This example highlights how a mutual lack of awareness between the official response and recovery agencies and NFP groups can result in what was described as "a discordant recovery process" (Ingham and Redshaw, 2017, p. 53). The value of working together has now been recognised, and initiatives developed to build better working 
relationships. Beyond the limited relationship with civil defence and other government authorities, other constraints such as funding and time impact on the potential of the nonprofit sector to contribute to building disaster resilience.

\section{Resourcing to supply emergency goods}

During the interviews, there was some discussion about supplying single parents who use NFPs with emergency items, such as basic disaster relief packages. While this seemed like a good response, the actuality of what would be required for NFP to access and maintain emergency supplies was problematic. Participants questioned how they would source the specific items to make emergency care packages and how they would keep the items current or even distribute them in a disaster. The following excerpts represent the types of conversations that occurred:

I don't know whether we could resource little emergency packs for families or something, with some water and some tinned food and a First Aid Kit and a torch that they just put away, so it's always there in the wardrobe if they needed it. (Eva)

... They would want water or food, and we probably wouldn't have an awful lot that day because our supply chain is from volunteers coming from the supermarkets, that pick up excess food .... (Gwen)

Although some have good relationships with some private sector services such as supermarkets, the NFP organisations in this study could not effectively work with their clients to increase their supply of reserve goods. The participants, and their colleagues, already carried demanding workloads, and their agencies did not have the funds to invest in extra staff or disaster risk reduction initiatives. This is narrated insightfully by the following participant:

Well, there's that basic law that there's only so many hours in the day, which the government don't seem to understand. . I know that people's caseloads are huge and I see my colleagues over at [other service of agency] rushing in trying to grab a glass of water and have a wee before they rush out again. And they're desperate because they probably needed to do that two hours ago, and so that's how busy they are. . . So I think the will is always there, but if you actually thought about how many man hours, for want of a better word, how many "man" hours, travel hours, thinking hours, organising hours, anything takes, even just organising to book a room here probably takes half an hour of someone's day to go to and from, when's it going to be, when's it going to be available, getting the flyer out, email out to people. That's going to take another hour, and so you sort of. . ., you get a picture of like just everything takes. .., yeah. It's not ever easy, and without funding for that it just becomes impossible, cos then that time, knowing people I work with, that time is their own time in the evening, catching up. (Gwen)

This excerpt represents how funding bodies overlook constraints of time with heavy caseloads, travel, reporting and other administrative obligations. While there are so many demands and escalating numbers of precariat groups (Groot et al., 2017), only 11\% of New Zealand's non-profit organisations have paid staff, and $7 \%$ have five or fewer employees, including part-time workers (Statistics New Zealand, 2020b). Raising and accounting for operating funds from diverse sources including donations, fundraising events and initiatives, philanthropic and government grants, membership fees and subscriptions and the sale of services (including government contracts) require expertise and time.

The constraints of limited staff hours and funds mean that non-profits must carefully weigh up their capacity to deliver contractual outputs against the potential benefit for their clients that any new opportunities might offer:

Everything for us depends on available funds, and so everything that we do is ruled by that, so we're always looking around to see what's needed and if we think there is a need for something then we will try, and source funding to at least set something up for a trial and see how it works. But yeah, we 
need to have the information provided so that we can base what we're going to do and then organise something, and see if we've got the actual available funds if it falls into what we've got funding for or whether we need to source other funding to actually put it into practice. (Mele)

The challenge of limited funding has been exacerbated by the recent response to COVID-19. A media report by Biddle (2020) argued that charities and NFP organisations were requesting financial rescue packages to get through the initial phases of the lockdown during COVID-19 and beyond. During lockdown, organisations were unable to continue many of their normal fundraising activities, which often required face-to-face interaction (Moe, 2020). It was a relief to see that when COVID-19 struck Aotearoa New Zealand, the government was able to resource certain NFP agencies to continue to provide everyday and additional COVID-19related services, such as temporary housing. Meanwhile, philanthropic trusts that fund the NFP sector are facing decreasing investment income alongside this (Philanthropy New Zealand, 23 March, 2020), while pressure on government expenditure will potentially limit financial support to the sector. Increased demand for services in the depressed economic conditions will also put extra stress and demand on social service agencies.

\section{Discussion and conclusions}

The perspectives of the participants in this research provide insight into the work, and potentiality, of NFP organisations in disaster risk management. NFPs in this work provide disaster preparedness messaging or education, and while not mandated everyone who participated in this study saw the value of it. Yet, while there is merit in helping to strengthen reliance, participants were concerned that promoting preparedness when people do not have the means to actually source the items required to be prepared because of social and financial barriers was unjust. They recognised that many of their single-parent clients survived on limited incomes and had rented and insecure housing. It was further delineated that there is a dearth of appropriate "fit for purpose" information to disseminate to people who use NFP organisations; much of the available disaster preparedness information overlooks the contextual situatedness of diverse people including single parents, people with disabilities, people who have English as a second language or the working poor. This lack of multiplicity in disaster messaging is of note, especially knowing that the NFP organisations in this study were located in places that continue to rebuild following the 2010/2011 Canterbury earthquake sequence (Vallance and Carlton, 2015) and the 2019 terrorist attack (Crothers and O’Brien, 2020).

Participants contemplated how their organisations could provide disaster preparedness kits, but realised that it was impossible due to monetary, time and staffing limitations although they were fully committed to supporting community well-being for single parents and understood the complexities of precariat lives. NFP groups often operate on donated time and resources (Statistics New Zealand, 2020b), rendering preparedness training and support inconsequential. Time constraints, more pressing everyday work matters when dealing with the complex effects of people living lives of hardship and limited organisational funding were reasons for not prioritising disaster preparedness planning with clients. NFP groups are unduly burdened with caring for precarious groups in a social system that can inadequately resource them for this work. Beyond the daily work struggles for NFPs, broader social and political factors also likely impact on these organisations and their ability to provide disaster preparedness support.

In that capacity, we recommend that these issues be addressed in the following ways:

(1) Provide social support and empower single parents and others who experience vulnerability to feel they have the means and backup and safety in the everyday and when the world is unstable and insecure.
Role of NFPs in disaster preparedness 
(2) Base disaster preparedness messaging on simple infographics forms of communication that do not overwhelm the reader.

(3) Provide additional funding, to support disaster resilience training for NFP and for single parents and others who experience vulnerability in everyday life and during extraordinary times. This funding should align with and enhance the pre-existing interests and agendas of NFP groups (O'Brien et al., 2009).

(4) Fund a disaster education coordinator to work across NFP and NGO sectors and walk alongside existing staff to support disaster readiness.

(5) Develop a more inclusive and sustainable disaster and emergency management framework that addresses the needs of precariat communities.

(6) Coordinate collaborative responses across government agencies, NFP and other communities to find an appropriate response to crisis events.

Without equitable relationships and substantive training and resourcing, NFPs will not be able to realise their potential to support disaster planning for precariat groups, including single parents. Regrettably, this is a lost opportunity in that NFP groups have a range of social and community capital to draw on. They engender a sense of community and trust with the people they work, such as single parents. The advocacy role of NFPs was seen as important to bridging and navigating difficult relationships between organisations such as welfare and health agencies, especially in times of distress.

A range of disaster research attests to the importance of taking account of the social and political vulnerability that significantly contributes to disaster outcomes, not just the physical and economic elements (Allen, 2006; Blake et al., 2017a, b; Tierney, 2019; Wisner et al., 2004). Precariat groups already endure the "disaster" of disadvantage due to the broader structural inequalities which must be mitigated to ensure flourishing after extraordinary events. As recognised during the COVID-19 Level 4 lockdown in Aotearoa New Zealand, the NFP sector provided "essential" services to enhance the well-being and safety of marginalised communities; the NFP organisations offer community and connection to people societies can often turn away from or overlook. To realise that potential, more attention should be given to the challenges identified in this research. If addressed in good faith and with mutual respect, social equity can be provided for all during tenuous disaster times and in the everyday.

\section{References}

Aitsi-Selmi, A. and Murray, V. (2015), "The Sendai framework: disaster risk reduction through a health lens", Bulletin of the World Health Organization, Vol. 93 No. 6, p. 362, doi: 10.2471/BLT.15.157362.

Aldrich, D.P. (2012), Building Resilience: Social Capital in Post-disaster Recovery, The University of Chicago Press, Chicago, IL.

Allen, K.M. (2006), "Community-based disaster preparedness and climate adaptation: local capacitybuilding in the Philippines", Disasters, Vol. 30 No. 1, pp. 81-101, doi: 10.1111/j.1467-9523.2006. 00308.x.

Beckjord, E.B., Stern, S., Meredith, L.S., Shugarman, L.R., Chandra, A., Tanielian, T., Taylor, S.L. and Parker, A.M. (2008), Enhancing Emergency Preparedness, Response, and Recovery Management for Vulnerable Populations, Health Working Paper, March, Santa Monica, CA.

Benson, C., Twigg, J. and Myers, M. (2001), "NGO initiatives in risk reduction: an overview”, Disasters, Vol. 25 No. 3, pp. 199-215.

Biddle, D.-L. (2020), Coronavirus: Small Charities, Non-profits, at Risk during Covid-19 Pandemic, Stuff, Retrieved 15th April from, available at: https://www.stuff.co.nz/national/health/ coronavirus/121010867/coronavirus-small-charities-nonprofits-at-risk-during-covid19pandemic. 
Blake, D. (2018), "Access to healthcare: opioid substitution treatment following a disaster in Aotearoa New Zealand", Australian Community Psychologist, Vol. 29 No. 1.

Blake, D., Marlowe, J. and Johnston, D. (2017a), "Get prepared: discourse for the privileged?", International Journal of Disaster Risk Reduction, pp. 283-288, doi: 10.1016/j.ijdrr.2017.09.012.

Blake, D., Miller, A. and Rampton, A. (2017b), "Get prepared for an emergency: an infographic", Australasian Journal of Disaster and Trauma Studies, Vol. 1 No. 21, available at: http://trauma. massey.ac.nz/issues/2017-1/AJDTS_21_1_Blake.pdf.

Blind Low Vision NZ (2020), Community: Tips for Navigating COVID-19 from a Blind and Low Vision Perspective, Blind Low Vision NZ, Wellington, available at: https://blindlowvision.org.nz/ community/tips-for-navigating-covid-19/ (accessed 17 July 2020).

Boyd, N.M. and Martin, E.C. (2020), "Sense of community responsibility at the forefront of crisis management", Administrative Theory and Praxis. doi: 10.1080/10841806.2020.1765288.

Christchurch City Council (2020), "Be prepared”, available at: https:/ccc.govt.nz/services/civil-defence/ being-prepared/.

Claridge, T. (2018), "Functions of social capital - bonding, bridging, linking", available at: https:// www.socialcapitalresearch.com/difference-bonding-bridging-social-capital/.

Cretney, R.M. (2016), "Local responses to disaster. The value of community led post disaster response action in a resilience framework", Disaster Prevention and Management, Vol. 25 No. 1, pp. 27-40, doi: 10.1108/DPM-02-2015-0043.

Crothers, C. and O'brien, T. (2020), "The contexts of the Christchurch terror attacks: social science perspectives", Kōtuitui: New Zealand Journal of Social Sciences Online, Vol. 15 No. 2, pp. 247-259.

Curnin, S. and O'Hara, D. (2019), "Nonprofit and public sector interorganizational collaboration in disaster recovery: lessons from the field", Nonprofit Management and Leadership, Vol. 20, pp. 277-297.

Farmer, P. (2004), "An anthropology of structural violence”, Current Anthropology, Vol. 45 No. 3, pp. 305-325, doi: 10.1086/382250.

Gibson, T. and Wisner, B. (2019), "Global overview of the role of NGOs in natural hazard governance natural hazard science", doi: 10.1093/acrefore/9780199389407.013.187.

Giddens, A. (1991), Modernity and Self-Identity: Self and Society in the Late Modern Age, Stanford University Press.

Good, G.A., Phibbs, S. and Williamson, K. (2016), "Disoriented and immobile: the experiences of people with visual impairments during and after the Christchurch, New Zealand, 2010 and 2011 earthquakes", Journal of Visual Impairment and Blindness, Vol. 111 No. 6, pp. 425-435.

Groot, S., Tassell-Matamua, N., Van Ommen, C. and Masters-Awatere, B. (2017), Precarity: Uncertain, Insecure and Unequal Lives in Aotearoa New Zealand, Massey University Press.

Guest, G., Bunce, A. and Johnson, L. (2006), "How many interviews are enough? An experiment with data saturation and variability", Family Health International, Vol. 18 No. 1, pp. 59-82, doi: 10. 1177/1525822X05279903.

Hawkins, R.L. and Maurer, K. (2011), "You fix my community, you have fixed my life': the disruption and rebuilding of ontological security in New Orleans", Disasters, Vol. 35 No. 1, pp. 143-159, doi: 10.1111/j.03613666.2010.01197.x.

Ho, K. (2007), "Structural violence as a human rights violation", Essex Human Rights Review, Vol. 4, p. 2.

Hodgetts, D. and Stolte, O. (2017), Urban Poverty and Health Inequalities: A Relational Approach, 1st ed., Routledge, Oxford.

Hodgetts, D., Chamberlain, K., Groot, S. and Tankel, Y. (2014), "Urban poverty, structural violence and welfare provision for 100 families in auckland”, Urban Studies, Vol. 51 No. 10, pp. 2036-2051, doi: 10.1177/0042098013505885. 
Ingham, V. and Redshaw, S. (2017), "Connecting community organisations for disaster preparedness", International Journal of Safety and Security Engineering, Vol. 7 No. 1, pp. 52-64, doi: 10.2495/ SAFE-V7-N1-52-64.

Jovita, H.D., Nashir, H., Mutiarin, D., Moner, Y. and Nurmandi, A. (2019), "Social capital and disasters: how does social capital shape post-disaster conditions in the Philippines?", Journal of Human Behavior in the Social Environment, Vol. 29 No. 4, pp. 519-534, doi: 10.1080/10911359.2018. 1556143.

Kapucu, N. (2007), "Non-profit response to catastrophic disasters", Disaster Prevention and Management, Vol. 16 No. 4, pp. 551-561, doi: 10.1108/09653560710817039.

Kapucu, N. (2008), “Culture of preparedness: household disaster preparedness”, Disaster Prevention and Management, Vol. 17 No. 4, pp. 526-535, doi: 10.1108/09653560810901773.

King, D., Rua, M. and Hodgetts, D. (2017), "How Māori precariat families navigate social services", in Groot, S., Tassell-Matamua, N., Ommen, C.V. and Masters-Awatere, B. (Eds), Precarity: Uncertain, Insecure and Unequal Lives in Aotearoa New Zealand, Massey University Press.

Lassa, J.A. (2018), "Roles of non-government organizations in disaster risk reduction", Natural Hazard Science. doi: 10.1093/acrefore/9780199389407.013.45.

Living wage Aotearoa New Zealand (2020), "Essential workers deserve a living wage”, Retrieved 5th September from, available at: https://www.livingwage.org.nz/essential_workers_deserve_a_ living_wage.

McMillan, D.W. (2011), "Sense of community, a theory not a value: a response to Nowell and Boyd", Journal of Community Psychology, Vol. 39 No. 5, pp. 507-519, doi: 10.1002/jcop.20439.

Ministry of Civil Defence and Emergency Management (2019), "National disaster resilience strategy", Rautaki $\bar{a}$-Motu Manawaroa Aitua a , available at: https://www.civildefence.govt.nz/cdem-sector/ plans-and-strategies/national-disaster-resilience-strategy/.

Ministry of Health (2016), Framework for Psychosocial Support in Emergencies, Ministry of Health, available at: http://www.health.govt.nz/publication/framework-psychosocial-supportemergencies.

Ministry of Health (2020), "COVID-19 - essential services in the health and disability system", Retrieved 5th August from, available at: https://www.health.govt.nz/our-work/diseases-andconditions/covid-19-novel-coronavirus/covid-19-current-situation/covid-19-essential-serviceshealth-and-disability-system.

Moe, S. (2020), "Charities, NFPs and COVID-19: where to? Institute of directors", Retrieved 11th August from, available at: https://www.iod.org.nz/resources-and-insights/news-and-articles/ charities-nfps-and-covid-19-where-to/\#.

National Emergency Management Agency (2020), “The 4Rs”, Retrieved 02 September from, available at: https://www.civildefence.govt.nz/cdem-sector/the-4rs/.

Neal, D.M. (1997), "Reconsidering the phases of disaster", International Journal of Mass Emergency and Disasters, Vol. 15 No. 2, pp. 239-256.

New Zealand Police Ngā Pirihimana o Aotearoa (2012), “Christchurch earthquake: list of deceased”, 21 August 2016, available at: http://www.police.govt.nz/major-events/previous/christchurchearthquake.

Not For Profit Resource (2017), "Definition of 'non-profit', 'not for profit organisation', 'charity' etc", Retrieved 13th July from, available at: https://www.not-for-profit.org.nz/define-a-not-for-profitorganisation/.

O’Brien, M., Sanders, J. and Tennant, M. (2009), The New Zealand Non-profit Sector and Government Policy, Office for the Community and Voluntary Sector, Wellington.

Pence, J. (2004), "Narrative emotion: feeling, form and function”, Journal of Narrative Theory, Vol. 34 No. 3, pp. 273-276, doi: 10.1353/jnt.2005.0005. 
Tipler, K., Tarrant, R., Johnston, D. and Tuffin, K. (2017), “Are you ready? Emergency preparedness in New Zealand schools”, International Journal of Disaster Risk Reduction, Vol. 25, pp. 324-333, doi: 10.1016/j.ijdrr.2017.09.035.

Twigg, J. (2009), "Characteristics of a disaster resilent community", A guidance note. Version 2, available at: www.abuhrc.org/research/dsm/Pages/project_view.aspx?project=13.

United Nations (2015), "Sendai framework for disaster risk reduction 2015-2030", available at: https:// www.preventionweb.net/files/43291_sendaiframeworkfordrren.pdf.

Vallance, S. and Carlton, S. (2015), "First to respond, last to leave: communities' roles and resilience across the “4Rs", International Journal of Disaster Risk Reduction, Vol. 14, pp. 27-36, doi: 10. 1016/j.ijdrr.2014.10.010.

Vulnerable Sections of Society Working Group Community Engagement Subcommittee (2015), "Vulnerable sections of society (an emergency management perspective)", available at: https:// knowledge.aidr.org.au/media/5938/vulnerable-sections-of-society-anzemc.pdf.

Wellington Regional Emergency Management Office (2018), "Preparedness guides", available at: https://wremo.nz/publications/preparedness-guides/.

Wisner, B., Blaikie, P., Cannon, T. and Davis, I. (2004), At Risk: Natural Hazards, People's Vulnerability and Disasters, Routledge, New York, NY.

\section{Corresponding author}

Denise Blake can be contacted at: d.blake@massey.ac.nz, denise.blake@vuw.ac.nz

For instructions on how to order reprints of this article, please visit our website: 